\title{
Effects of Improving Glycemic Control with Insulin on Leptin, Adiponectin, Ghrelin and Neuropeptidey Levels in Patients with Type 2 Diabetes Mellitus: a Pilot Study
}

\author{
Niki Katsiki ${ }^{1,2}$, Dimitri P. Mikhailidis ${ }^{2, *}$, Anna Gotzamani-Psarrakou ${ }^{3}$, Triantafillos P. Didangelos ${ }^{1}$, \\ John G. Yovos ${ }^{4}$ and Dimitrios T. Karamitsos ${ }^{1}$
}

\author{
${ }^{I}$ First Propedeutic Department of Internal Medicine, AHEPA University Hospital, Aristotle University of Thessaloniki, \\ Thessaloniki, Greece \\ ${ }^{2}$ Department of Clinical Biochemistry, Royal Free Campus, University College London Medical School, University \\ College London (UCL), London, UK \\ ${ }^{3} 2^{\text {nd }}$ Laboratory of Nuclear Medicine, AHEPA University Hospital, Aristotle University of Thessaloniki, Thessaloniki, Greece \\ ${ }^{4}$ Department of Endocrinology and Metabolism, AHEPA University Hospital, Aristotle University of Thessaloniki, \\ Thessaloniki, Greece
}

\begin{abstract}
Objective: Insulin therapy is associated with weight gain in patients with type 2 diabetes mellitus (T2DM). Several peptides are implicated in appetite control. We evaluated the effects of insulin-induced improved glycaemic control on leptin, adiponectin, ghrelin, neuropeptide Y (NPY) levels and patient characteristics.

Method: Consecutive T2DM patients $(\mathrm{n}=90)$ were divided into 2 groups: Group A: 45 insulin-naïve uncontrolled (glycosylated haemoglobin $\mathrm{A}_{1 \mathrm{c}} ; \mathrm{HbA}_{1 \mathrm{c}}>7 \%$ ) patients on oral hypoglycaemic agents (OHAs) who converted to insulin monotherapy. Group B: 45 well-controlled $\left(\mathrm{HbA}_{1 \mathrm{c}}<7 \%\right)$ patients on OHAs. Both groups were monitored at baseline, 3 and 6 months. Males and females were analyzed separately because some hormone levels differ between genders.

Results: In both genders, insulin therapy (Group A) was associated with significant $(\mathrm{p}=0.003$ to $<0.001)$ increases in weight, body mass index and leptin levels and significant decreases in glucose, $\mathrm{HbA}_{1 \mathrm{c}}$ and NPY levels. In male insulintreated patients a significant increase in adiponectin levels $(\mathrm{p}=0.008)$ was observed. There were significant correlations ( $\mathrm{p}=0.016$ to $<0.001)$ between leptin levels, waist circumference and body fat in all patient groups, except group B males.
\end{abstract}

Conclusion: Changes in leptin, adiponectin and NPY levels may occur after insulin-induced improved glycaemic control. These changes may be influenced by gender, weight, body fat and $\mathrm{HbA}_{1 \mathrm{c}}$.

Keywords: Gender, glycosylated haemoglobin $\mathrm{A}_{1 \mathrm{c}}$, insulin, type 2 diabetes mellitus, weight gain.

\section{INTRODUCTION}

In patients with type 2 diabetes mellitus (T2DM) tight glycaemic control with either intensive insulin therapy or sulfonylureas has been associated with weight gain $[1,2]$. However, insulin-treated patients gained more weight compared with those on oral hypoglycaemic agents (OHAs) [2].

The underlying mechanisms causing insulin-induced weight gain are only partly understood and include (apart from the correction of dehydration in some cases) the anabolic effects of insulin, stimulation of lipogenesis, suppression of hepatic glucose production, reduction of basal metabolic rate and elimination of glycosuria $[1,3,4]$. Furthermore, fear of hypoglycaemia and a feeling of freedom to eat in

\footnotetext{
*Address correspondence to this author at the Dept. of Clinical Biochemistry (Vascular Disease Prevention Clinics), Royal Free Hospital Campus, University College London Medical School, University College London (UCL), Pond Street, London NW3 2QG, UK; Tel: 0044 (0) 207830 2258; Fax: 0044 (0) 207830 2235;

E-mails: MIKHAILIDIS@aol.com,mikhailidis@hotmail.com
}

patients on insulin therapy may account for additional food consumption $[3,5]$. On the other hand, a central effect of insulin has also been proposed with insulin and leptin resistance leading to reduced satiety signaling to the hypothalamus despite overfeeding and hyperinsulinaemia $[3,6]$.

Nutrients and gastrointestinal hormones like ghrelin are considered as short-term signals that influence food intake [7]. In contrast, insulin and leptin act as long-term regulators that ensure stability of body weight and adiposity and maintenance of energy homeostasis over a more prolonged period of time [7]. These regulators transfer information from the periphery to the central nervous system, where they modulate neuropeptide release which in turn influences appetite and energy expenditure [8]. In particular, leptin stimulates the expression of anorexigenic neuropeptides and inhibits the expression of orexigenic neuropeptides, such as neuropeptide Y (NPY), therefore suppressing food intake and enhancing energy expenditure [8]. Both central and peripheral adiponectin administration reduced body weight via either food intake suppression or increased energy expenditure [9]. 
Ghrelin increases NPY expression in the hypothalamus and blocks leptin-induced satiety, subsequently leading to increased food intake [10].

In this pilot study we evaluated the effect of insulininduced improvement of glycaemic control on adipokines (i.e. leptin and adiponectin), a gut peptide (i.e. ghrelin) and a neuropeptide (i.e. NPY) levels, weight parameters, lipids and renal function in patients with T2DM. We also considered the possible correlations between these variables.

\section{MATERIALS AND METHODS}

\section{Study Population}

A total of 90 consecutive patients with T2DM were recruited from the Diabetes Outpatient Clinic, AHEPA University Hospital, Thessaloniki, Greece. The study population was divided into 2 groups: Group A consisted of 45 insulinnaïve poorly controlled (glycosylated haemoglobin $\mathrm{A}_{1 \mathrm{c}}$; $\mathrm{HbA}_{1 \mathrm{c}}>7 \%$ ) patients on OHAs who were converted to insulin monotherapy (2 daily injections of biphasic isophane insulin). Group B consisted of 45 well-controlled $\left(\mathrm{HbA}_{1 \mathrm{c}}<7 \%\right)$ patients on OHAs. All patients in group B were taking metformin $(800 \mathrm{mg}$, twice daily) and 30 of them were also taking sulfonylureas, mainly gliclazide $(80 \mathrm{mg}, 2$ or 3 times daily). Patients with history of impaired liver or kidney function, malignancy, endocrinopathy or on corticosteroid treatment were excluded. All women were postmenopausal and were not on hormone replacement therapy.

Patients on thiazolidinediones were excluded as these agents may influence leptin (rosiglitazone) [11], adiponectin (rosiglitazone [12] and pioglitazone [13]) and ghrelin levels (rosiglitazone) [14].

\section{Study Design}

Both groups were prospectively followed up for 6 months and monitored on an outpatient basis at baseline, 3 and 6 months. In the insulin-treated group, dose adjustments were based on home blood glucose monitoring. At every evaluation, physical examination including weight, height, waist circumference (WC) and blood pressure measurements, determination of percentage of body fat by bioimpedance analysis (SKYLARK BT-905, Taiwan) and laboratory analyses (white cell count (WCC), glucose, $\mathrm{HbA}_{1 c}$, creatinine $(\mathrm{Cr})$, uric acid, alanine aminotransferase (ALT), aspartate aminotransferase (AST), gamma-glutamyl transpeptidase (gamma-GT), creatine kinase (CK), total cholesterol (TC), triglycerides (TG), high density lipoprotein cholesterol (HDL-C), low density lipoprotein cholesterol (LDL-C), leptin, adiponectin, ghrelin and NPY) were performed in all patients.

Body mass index $\left(\mathrm{BMI}=\right.$ weight $/$ height $\left.^{2}\right)$, estimated glomerular filtration rate (eGFR) based on the Modification of Diet in Renal Disease (MDRD) formula (http://nephron. org/mdrd_gfr_si) and creatinine clearance based on the Cockroft-Gault formula (http://clinicalculator.com/english/ nephrology/cockroft/cca.htm) were also calculated.

At baseline, patients were interviewed by a qualified dietician. A specific 7-day diet sheet was given to each patient at every visit. Daily calorie intake was 500 calories below the needs of the patient, taking into account the individual's physical activity. The patients were advised to maintain the same diet and level of physical activity throughout the study.

The study was approved by the local ethics committee and informed consent was obtained from all participants.

\section{Blood Sample Collection and Analysis}

All blood samples were collected in the morning after an overnight fast (water allowed) and divided into 2 samples of $10 \mathrm{ml}$ each. The first $10 \mathrm{ml}$ were immediately analyzed for routine laboratory parameters (WCC, glucose, $\mathrm{HbA}_{1 \mathrm{c}}, \mathrm{Cr}$, uric acid, ALT, AST, gamma-GT, CK, TC, TG, HDL-C and LDL-C). The second $10 \mathrm{ml}$, after centrifugation at $4^{\circ} \mathrm{C}$, were stored in aliquots at $-20^{\circ} \mathrm{C}$ until assayed for leptin, total adiponectin, total ghrelin and NPY using commercially available radioimmunoassay kits (Linco Research Inc., St. Charles, MO, USA for leptin, adiponectin and ghrelin; EuroDiagnostica Inc., Malmö, Sweden for NPY). It is known that ghrelin circulates in 2 forms: octanoylated (acylated) and desacylated. Although only acylated ghrelin is bioactive, levels of total ghrelin are a good surrogate for those of acylated ghrelin because the ratio of the 2 remains constant under a wide variety of conditions $[15,16]$.

Regarding intra- and inter-assay variations, for leptin, intra-assay variation is $8.3,4.6,3.9,4.7$ and $3.4 \% \mathrm{CV}$ for 5 varying concentrations of leptin, i.e. 4.9, 7.2, 10.4, 15.7 and $25.6 \mathrm{ng} / \mathrm{ml}$, respectively, whereas inter-assay variation is 6.2 , 5.0, 4.7, 3.0 and 3.6\% CV 4.9, 7.2, 10.4, 15.7 and 25.6 $\mathrm{ng} / \mathrm{ml}$, respectively.

For adiponectin, intra-assay precision is $3.59,6.21$ and $1.78 \% \mathrm{CV}$ for low $(3 \mathrm{ng} / \mathrm{ml})$, middle $(6 \mathrm{ng} / \mathrm{ml})$ and high $(15$ $\mathrm{ng} / \mathrm{ml}$ ) concentration of adiponectin, respectively, whereas inter-assay precision is $9.25,6.9$ and $9.25 \% \mathrm{CV}$ for low, middle and high adiponectin levels, respectively.

For total ghrelin, intra-assay variation is $10.0,3.3,7.9$ and $4.4 \% \mathrm{CV}$ for 4 varying concentrations of ghrelin, i.e. $1000,1500,2000$ and $3000 \mathrm{pg} / \mathrm{ml}$, respectively, whereas inter-assay variation is $14.7,17.8,16.0$ and $16.7 \% \mathrm{CV}$ for $1000,1500,2000$ and $3000 \mathrm{pg} / \mathrm{ml}$, respectively.

For NPY, intra-assay precision is 3.9 and $2.6 \% \mathrm{CV}$ for 57.9 and $100 \mathrm{pmol} / \mathrm{L}$ respectively, whereas inter-assay precision is 12.7 and $10.5 \% \mathrm{CV}$ for 59.1 and $98.9 \mathrm{pmol} / \mathrm{L}$, respectively.

\section{Statistical Analysis}

Statistical analyses were performed using the SPSS version 13.0 software package (SPSS Inc., Chicago, USA). Values are expressed either as mean \pm SD for parametric variables or as median (range) for non parametric ones. Differences between groups at baseline, 3 and 6 months were analyzed by Student's t test, Mann Whitney and $\chi^{2}$ test for parametric, non parametric continuous and categorical variables, respectively. Repeated measures ANOVA or the non-parametric alternative Friedman test was used to compare related samples data throughout the study. Correlations between the 4 peptides and various parameters were deter- 
mined by Pearson $r$ or Spearman Rho correlation analyses. Due to multiple comparisons, significance was set at $p$ $(2$-tailed $) \leq 0.025[17]$.

Males and females were considered separately because leptin and adiponectin levels differ significantly between genders $[18,19]$. Furthermore, patients were recruited sequentially and therefore we could not ensure equal gender distribution in both groups. In order to verify our results we also assessed the correlations between glucose and $\mathrm{HbA}_{1 \mathrm{c}}$ [20], as well as between body fat and WC [21].

\section{RESULTS}

\section{Results at Baseline}

\section{Male Patients (Table 1)}

Groups A and B were similar for hypertension, statin treatment, cardiovascular disease (CVD), smoking, age, weight, height, BMI, WC, duration of diabetes, systolic blood pressure (SBP), diastolic blood pressure (DBP), WCC, uric acid, HDL-C, LDL-C, AST, ALT, CK, Cr, leptin, adiponectin, ghrelin, NPY, MDRD eGFR and Cockroft-Gault creatinine clearance. However, in group B body fat was significantly higher $(\mathrm{p}=0.005)$, whereas TC $(\mathrm{p}=0.005), \mathrm{TG}(\mathrm{p}$ $=0.012)$ and gamma-GT $(\mathrm{p}=0.012)$ were significantly lower compared with group A.

\section{Female Patients (Table 2)}

Groups A and B were similar for hypertension, statin treatment, CVD, smoking, age, weight, height, WC, duration of diabetes, SBP, WCC, uric acid, TG, HDL-C, LDL-C, AST, ALT, CK, gamma-GT, Cr, leptin, adiponectin, MDRD eGFR and Cockroft-Gault creatinine clearance. However, in group B BMI $(p=0.009)$ and body fat $(p<0.001)$ were significantly higher, whereas DBP $(p=0.013)$, TC $(p=0.022)$, ghrelin $(\mathrm{p}=0.019)$ and NPY $(\mathrm{p}=0.021)$ were significantly lower compared with group A.

For both genders we did not compare glucose and $\mathrm{HbA}_{1 \mathrm{c}}$ values at baseline since we defined group $\mathrm{A}$ as uncontrolled and group B as well-controlled patients with T2DM.

\section{Results at 3 Months}

\section{Male Patients (Table 3)}

NPY levels were higher in group B compared with group $\mathrm{A}(\mathrm{p}=0.017)$.

\section{Female Patients (Table 4)}

Body fat was higher $(\mathrm{p}=0.004)$ and HDL-C levels were lower $(p=0.001)$ in group B compared with group A.

\section{Results at 6 Months}

\section{Male Patients (Table 5)}

Fasting glucose $(\mathrm{p}=0.005)$ and leptin levels were lower $(\mathrm{p}=0.003)$ in group B compared with group A.

\section{Female Patients (Table 6)}

Ghrelin levels were lower $(\mathrm{p}<0.001)$ and NPY levels were higher $(p=0.01)$ in group $B$ compared with group A.

\section{Changes Throughout the Study in Groups A and B}

\section{Male Patients}

In group A weight $(\mathrm{p}<0.001)$, BMI $(\mathrm{p}<0.001)$, leptin $(\mathrm{p}<0.001)$ and adiponectin levels $(\mathrm{p}=0.008)$ increased significantly, whereas fasting glucose $(\mathrm{p}<0.001), \mathrm{HbA}_{1 \mathrm{c}}$ $(\mathrm{p}<0.001)$ and NPY levels $(\mathrm{p}<0.001)$ decreased significantly. No differences were observed in group B male patients.

\section{Female Patients}

In group A weight $(\mathrm{p}=0.001), \mathrm{BMI}(\mathrm{p}<0.001)$, HDL-C $(p=0.002)$ and leptin levels $(p=0.003)$ increased significantly, whereas fasting glucose $(\mathrm{p}<0.001), \mathrm{HbA}_{1 \mathrm{c}}(\mathrm{p}<$ $0.001)$, DBP $(p=0.003)$, TG $(p=0.006)$ and NPY levels $(p$ $<0.001)$ decreased significantly. In group B female patients, body fat $(\mathrm{p}=0.002)$, AST $(\mathrm{p}=0.012)$ and ghrelin levels $(\mathrm{p}<$ $0.001)$ were significantly reduced.

\section{Correlations}

Leptin levels significantly correlated with WC and body fat in all patient groups, except group B male patients (Table 7).

As expected, glucose correlated significantly with $\mathrm{HbA} 1 \mathrm{c}$ in all groups and at all times $(p=0.019$ to $<0.0001)$, except for group A females at baseline and 3 months. Furthermore, body fat correlated significantly with $\mathrm{WC}$ in all groups and at all times $(\mathrm{p}=0.01$ to $<0.0001)$, except group B male patients (Table 7).

\section{DISCUSSION}

Leptin levels were higher in females compared with males in each group, at all sampling points during the study ( $\mathrm{p} \leq 0.001$ for all comparisons). These findings are consistent with previous results in T2DM patients on various hypoglycaemic treatments [18]. Adiponectin concentrations were non-significantly higher in females in each group, at baseline and at 6 months. Circulating adiponectin levels are reported to be higher in females with or without DM in some but not all studies [19, 22, 23]. No significant gender differences in ghrelin concentrations were found in each group at all sampling points during the study. This is in agreement with reports in nondiabetic individuals [24], although higher circulating ghrelin concentrations in nondiabetic females have been documented [25]; data in T2DM patients are lacking. NPY levels did not differ significantly between genders in each group at all times during the study. No literature regarding gender differences for NPY were found.

Some of the differences we observed between groups at baseline may be attributed to the uncontrolled patients being more concerned about their lifestyle (e.g. weight). Uncontrolled group A females had significantly higher baseline ghrelin levels compared with well-controlled group B female patients $(p=0.019)$. In contrast, others reported that patients with T2DM had lower ghrelin levels when long-term glycaemic control was poor [26]. The observed lower baseline ghrelin concentrations in group B females may be attributed to their higher BMI and body fat compared with group A females, as ghrelin levels are negatively correlated with both 
Table 1. Baseline Clinical and Fasting Laboratory Characteristics of Male Patients with type 2 Diabetes Mellitus

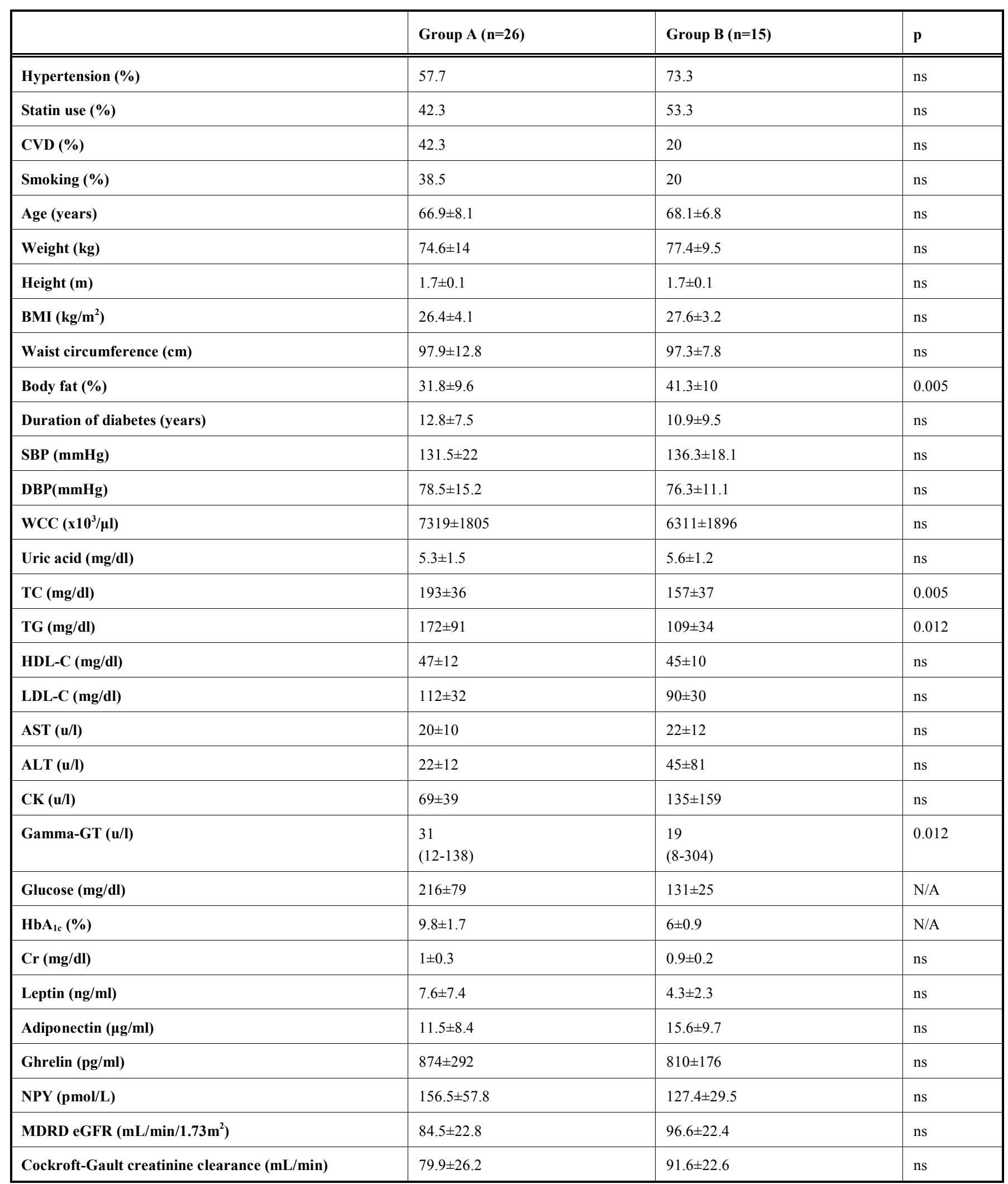

CVD: cardiovascular disease (coronary heart disease and/or stroke); BMI: body mass index; SBP: systolic blood pressure; DBP: diastolic blood pressure; WCC: white cell count; TC: total cholesterol; TG: triglyceride; HDL-C: high density lipoprotein cholesterol; LDL-C: low-density lipoprotein cholesterol; AST: aspartate transaminase; ALT: alanine transaminase; CK: creatine kinase; gamma-GT: gamma glutamyl transpeptidase; Cr: creatinine; NPY: neuropeptide Y; MDRD: modification of diet in renal disease; eGFR: estimated glomerular filtration rate; N/A: not applicable. 
Table 2. Baseline Clinical and Fasting Laboratory Characteristics of Female Patients with Type 2 Diabetes Mellitus

\begin{tabular}{|c|c|c|c|}
\hline & Group A $(n=19)$ & Group B $(n=30)$ & $\mathbf{p}$ \\
\hline Hypertension (\%) & 63.2 & 83.3 & $\mathrm{~ns}$ \\
\hline CVD (\%) & 21.1 & 16.7 & ns \\
\hline Smoking (\%) & 31.6 & 13.3 & ns \\
\hline Weight (kg) & $69.1 \pm 19.4$ & $75.3 \pm 14.2$ & ns \\
\hline Height (m) & $1.6 \pm 0.1$ & $1.6 \pm 0.1$ & ns \\
\hline BMI $\left(\mathrm{kg} / \mathrm{m}^{2}\right)$ & $27.1 \pm 7.2$ & $31 \pm 4.9$ & 0.009 \\
\hline Waist circumference (cm) & $96.6 \pm 16.8$ & $105.8 \pm 13$ & ns \\
\hline SBP (mmHg) & $141.1 \pm 19.8$ & $136.3 \pm 16.6$ & ns \\
\hline DBP(mmHg) & $85.8 \pm 13.1$ & $75.7 \pm 11.4$ & 0.013 \\
\hline $\operatorname{WCC}\left(\mathrm{x}^{10} 0^{3} / \mu \mathrm{l}\right)$ & $7799 \pm 3277$ & $7132 \pm 1551$ & $\mathrm{~ns}$ \\
\hline Uric acid (mg/dl) & $4.5 \pm 1.6$ & $5.5 \pm 1.4$ & $\mathrm{~ns}$ \\
\hline TC (mg/dl) & $222 \pm 45$ & $192 \pm 41$ & 0.022 \\
\hline TG (mg/dl) & $\begin{array}{l}160 \\
(69-620)\end{array}$ & $\begin{array}{l}129 \\
(69-542)\end{array}$ & $\mathrm{ns}$ \\
\hline HDL-C (mg/dl) & $58 \pm 18$ & $49 \pm 12$ & ns \\
\hline Gamma-GT (u/l) & $\begin{array}{l}17 \\
(12-120)\end{array}$ & $\begin{array}{l}15 \\
(10-53)\end{array}$ & $\mathrm{ns}$ \\
\hline Glucose (mg/dl) & $232 \pm 59$ & $136 \pm 35$ & N/A \\
\hline $\mathrm{HbA}_{1 \mathrm{c}}(\%)$ & $10.3 \pm 1.7$ & $6.2 \pm 0.7$ & N/A \\
\hline $\mathrm{Cr}(\mathrm{mg} / \mathrm{dl})$ & $0.8 \pm 0.3$ & $0.8 \pm 0.2$ & $\mathrm{~ns}$ \\
\hline Leptin (ng/ml) & $14.3 \pm 8.8$ & $17.8 \pm 8.1$ & $\mathrm{~ns}$ \\
\hline Adiponectin ( $\mu \mathrm{g} / \mathrm{ml})$ & $15.9 \pm 8.4$ & $16.8 \pm 11.1$ & $\mathrm{~ns}$ \\
\hline Ghrelin (pg/ml) & $934 \pm 245$ & $809 \pm 314$ & 0.019 \\
\hline NPY $(\mathbf{p m o l} / \mathbf{L})$ & $186.1 \pm 71.9$ & $140.9 \pm 45.7$ & 0.021 \\
\hline MDRD eGFR $\left(\mathrm{mL} / \mathrm{min} / 1.73 \mathrm{~m}^{2}\right)$ & $82.8 \pm 30.9$ & $88.6 \pm 28.2$ & ns \\
\hline Cockroft-Gault creatinine clearance $(\mathrm{mL} / \mathrm{min})$ & $87.2 \pm 54.5$ & $95.8 \pm 38.4$ & $\mathrm{~ns}$ \\
\hline
\end{tabular}

For abbreviations see Table $\mathbf{1}$.

BMI and body fat in T2DM patients [27]. However, ghrelin levels remained significantly higher in group A females compared with group B females $(p<0.001) 6$ months after initiation of insulin therapy, even though BMI and body fat became similar between these groups. 
Table 3. Fasting Laboratory and Other Characteristics of Male Patients with Type 2 Diabetes Mellitus at 3 Months

\begin{tabular}{|c|c|c|c|}
\hline & Group A $(n=26)$ & Group B (n=15) & $\mathbf{p}$ \\
\hline Weight (kg) & $76.1 \pm 14.4$ & $77.5 \pm 9.4$ & ns \\
\hline BMI $\left(\mathrm{kg} / \mathrm{m}^{2}\right)$ & $26.9 \pm 4.2$ & $27.7 \pm 3.3$ & ns \\
\hline Waist circumference (cm) & $96.7 \pm 12.4$ & $98.1 \pm 8.3$ & ns \\
\hline Body fat (\%) & $34.5 \pm 13$ & $37.5 \pm 6.8$ & ns \\
\hline SBP (mmHg) & $137.7 \pm 18.2$ & $133.7 \pm 12.9$ & ns \\
\hline DBP(mmHg) & $76.9 \pm 12.1$ & $76.7 \pm 10.5$ & $\mathrm{~ns}$ \\
\hline $\operatorname{WCC}\left(\times 10^{3} / \mu \mathrm{l}\right)$ & $6782 \pm 2174$ & $6953 \pm 1472$ & $\mathrm{~ns}$ \\
\hline Uric acid (mg/dl) & $5.7 \pm 1.5$ & $5.7 \pm 0.9$ & ns \\
\hline TC (mg/dl) & $190 \pm 49$ & $173 \pm 28$ & $\mathrm{~ns}$ \\
\hline TG (mg/dl) & $129 \pm 58$ & $136 \pm 53$ & ns \\
\hline HDL-C (mg/dl) & $48 \pm 10$ & $48 \pm 11$ & $\mathrm{~ns}$ \\
\hline LDL-C (mg/dl) & $116 \pm 40$ & $97 \pm 23$ & $\mathrm{~ns}$ \\
\hline $\operatorname{AST}(\mathbf{u} / \mathbf{l})$ & $19 \pm 5$ & $21 \pm 9$ & $\mathrm{~ns}$ \\
\hline $\operatorname{ALT}(\mathbf{u} / \mathbf{l}))$ & $19 \pm 7$ & $23 \pm 11$ & $\mathrm{~ns}$ \\
\hline CK (u/l) & $106 \pm 60$ & $99 \pm 86$ & $\mathrm{~ns}$ \\
\hline Gamma-GT (u/l) & $\begin{array}{l}30 \\
(10-75)\end{array}$ & $\begin{array}{l}17 \\
(10-475)\end{array}$ & ns \\
\hline Glucose (mg/dl) & $151 \pm 51$ & $123 \pm 31$ & ns \\
\hline $\mathrm{HbA}_{1 \mathrm{c}}(\%)$ & $7 \pm 1.6$ & $5.8 \pm 0.9$ & N/A \\
\hline $\mathrm{Cr}(\mathrm{mg} / \mathrm{dl})$ & $0.9 \pm 0.3$ & $0.9 \pm 0.2$ & $\mathrm{~ns}$ \\
\hline Leptin (ng/ml) & $10.4 \pm 7.7$ & $6.7 \pm 4.3$ & $\mathrm{~ns}$ \\
\hline Adiponectin $(\mu \mathrm{g} / \mathrm{ml})$ & $15 \pm 11.6$ & $11.7 \pm 7.3$ & $\mathrm{~ns}$ \\
\hline Ghrelin (pg/ml) & $933 \pm 574$ & $801 \pm 227$ & $\mathrm{~ns}$ \\
\hline NPY (pmol/L) & $111.7 \pm 26.3$ & $133.4 \pm 27.6$ & 0.017 \\
\hline MDRD eGFR (mL/min/1.73 m²) & $87.1 \pm 24.7$ & $95.5 \pm 27.1$ & $\mathrm{~ns}$ \\
\hline Cockroft-Gault creatinine clearance (mL/min) & $84.7 \pm 32.9$ & $90.8 \pm 25.5$ & ns \\
\hline
\end{tabular}

For abbreviations see Table $\mathbf{1}$.

Group A males had higher leptin levels than group B males at 6 months. This agrees with previous reports of higher leptin concentrations in T2DM patients on insulin therapy compared with those on other hypoglycaemic treatment [18].

Group A females had significantly higher HDL-C concentrations compared with group B females at 3 months ( $p=$ 0.001). This difference may be attributed to the insulininduced improvement of $\mathrm{HbA}_{1 \mathrm{c}}$ observed at 3 months, as good glycaemic control is associated with increased HDL-C levels in T2DM patients [28]. However, no similar results were observed in our male patients.

In the present study, after 6 months of insulin therapy, weight, BMI and leptin levels significantly increased, whereas fasting glucose, $\mathrm{HbA}_{1 \mathrm{c}}$ and NPY levels significantly decreased in both males and females. These insulinassociated changes have been reported [29-32], although without considering genders separately.

Aas et al., suggested that, since the increase in leptin concentrations precedes weight gain during insulin therapy, insulin per se and not increased fat mass is responsible for the observed changes [30]. The sustained rise in body weight despite the significant simultaneous increase in leptin levels may be explained by leptin resistance in diabetic patients [32].

Adiponectin levels significantly increased only in insulin-treated males. Similarly, Miyashita et al., [33] reported that adiponectin concentrations increased in patients with 
Table 4. Fasting Laboratory and Other Characteristics of Female Patients with type 2 Diabetes Mellitus at 3 Months

\begin{tabular}{|c|c|c|c|}
\hline & Group A $(n=19)$ & Group B $(n=30)$ & $\mathbf{p}$ \\
\hline Weight (kg) & $72.6 \pm 19.9$ & $75.3 \pm 13.9$ & $\mathrm{~ns}$ \\
\hline BMI $\left(\mathrm{kg} / \mathrm{m}^{2}\right)$ & $28.5 \pm 7.4$ & $31.1 \pm 4.9$ & ns \\
\hline Waist circumference (cm) & $100.9 \pm 17.2$ & $104.9 \pm 12.1$ & ns \\
\hline Body fat (\%) & $39.2 \pm 8.6$ & $46.3 \pm 6.2$ & 0.004 \\
\hline SBP (mmHg) & $136.3 \pm 22.1$ & $181.8 \pm 270.3$ & ns \\
\hline DBP(mmHg) & $75.5 \pm 13.8$ & $77.3 \pm 12$ & ns \\
\hline $\operatorname{WCC}\left(\times 10^{3} / \mu \mathrm{l}\right)$ & $6840 \pm 1693$ & $7387 \pm 1515$ & ns \\
\hline Uric acid (mg/dl) & $4.9 \pm 1.3$ & $5.6 \pm 1.3$ & ns \\
\hline TC (mg/dl) & $196 \pm 40$ & $196 \pm 42$ & ns \\
\hline TG (mg/dl) & $125 \pm 57$ & $168 \pm 94$ & ns \\
\hline HDL-C (mg/dl) & $65 \pm 18$ & $50 \pm 12$ & 0.001 \\
\hline LDL-C (mg/dl) & $106 \pm 34$ & $113 \pm 30$ & ns \\
\hline $\operatorname{AST}(u / l)$ & $23 \pm 10$ & $20 \pm 6$ & ns \\
\hline $\operatorname{ALT}(\mathbf{u} / \mathbf{l})$ & $25 \pm 15$ & $22 \pm 9$ & ns \\
\hline CK (u/l) & $83 \pm 34$ & $97 \pm 73$ & ns \\
\hline Gamma-GT (u/l) & $\begin{array}{l}15 \\
(7-292)\end{array}$ & $\begin{array}{l}16 \\
(10-79)\end{array}$ & ns \\
\hline Glucose (mg/dl) & $141 \pm 50$ & $141 \pm 34$ & ns \\
\hline $\mathrm{HbA}_{1 \mathrm{c}}(\%)$ & $7.2 \pm 1.4$ & $6.2 \pm 0.8$ & N/A \\
\hline $\mathrm{Cr}(\mathrm{mg} / \mathrm{dl})$ & $0.8 \pm 0.2$ & $0.8 \pm 0.2$ & ns \\
\hline Leptin (ng/ml) & $23.4 \pm 13.5$ & $20.2 \pm 10.9$ & ns \\
\hline Adiponectin $(\mu \mathrm{g} / \mathrm{ml})$ & $12.9 \pm 11.5$ & $11.3 \pm 5.3$ & ns \\
\hline Ghrelin (pg/ml) & $907 \pm 284$ & $836 \pm 315$ & ns \\
\hline NPY (pmol/L) & $118.9 \pm 22.9$ & $137.4 \pm 43.8$ & ns \\
\hline MDRD eGFR (mL/min/1.73 $\left.\mathrm{m}^{2}\right)$ & $88.3 \pm 25.9$ & $87.9 \pm 31.4$ & ns \\
\hline Cockroft-Gault creatinine clearance $(\mathrm{mL} / \mathrm{min})$ & $95.7 \pm 48.3$ & $94.1 \pm 36.2$ & ns \\
\hline
\end{tabular}

For abbreviations see Table $\mathbf{1}$.

T2DM after initiation of insulin treatment (twice-daily biphasic insulin analogue). In contrast, Jacob et al., reported a non significant trend for a reduction in adiponectin levels in T2DM patients on insulin monotherapy or insulin plus metformin [29]. These discrepancies could be explained by differences in sample size and $\mathrm{HbA}_{1 \mathrm{c}}$ values achieved. Furthermore, neither Miyashita et al., [33] nor Jacob et al., [29] analyzed their results according to gender.

Ghrelin levels did not change significantly in the insulin monotherapy groups, as previously reported [31]. In contrast, Jacob et al., documented significant decreases in ghrelin concentrations after initiation of insulin therapy in T2DM patients [29].

It has been demonstrated that NPY is expressed and secreted by adipose tissue and that peripherally administered insulin stimulates the release of adipogenic NPY [34]. As NPY has been reported to exert antilipolytic properties, hyperinsulinemia may lead to an increase in adiposity via elevated circulating NPY levels [34]. These interactions may partly explain the hyperinsulinemia-related weight gain. In contrast, in the present study, NPY levels significantly decreased in both males and females following the initiation of insulin therapy. Leptin has been reported to suppress the hypothalamic expression of NPY [35]; thus increased leptin levels may lead to reductions in NPY concentrations in both the hypothalamus and the circulation. It should be noted that we do not know if circulating NPY levels represent changes in the hypothalamus. There is evidence that NPY can cross the blood brain barrier [36] but this has only been demonstrated in animals. The fall in NPY levels observed in our study may reflect a complex interaction of several factors 
Table 5. Fasting Laboratory and Other Characteristics of Male Patients with Type 2 Diabetes Mellitus at 6 Months

\begin{tabular}{|c|c|c|c|}
\hline & Group A $(n=26)$ & Group B (n=15) & $\mathbf{p}$ \\
\hline Waist circumference (cm) & $100.5 \pm 12.1$ & $97.1 \pm 9.1$ & ns \\
\hline Body Fat (\%) & $34.6 \pm 10.1$ & $35.9 \pm 8$ & $\mathrm{~ns}$ \\
\hline DBP(mmHg) & $78.9 \pm 12.8$ & $73 \pm 5.9$ & ns \\
\hline WCC $\left(x 10^{3} / \mu \mathrm{I}\right)$ & $7425 \pm 1906$ & $6269 \pm 1389$ & $\mathrm{~ns}$ \\
\hline Uric acid (mg/dl) & $5.5 \pm 1.7$ & $5.8 \pm 0.9$ & $\mathrm{~ns}$ \\
\hline TC (mg/dl) & $188 \pm 61$ & $171 \pm 32$ & ns \\
\hline HDL-C (mg/dl) & $45 \pm 10$ & $47 \pm 8$ & ns \\
\hline LDL-C (mg/dl) & $108 \pm 33$ & $97 \pm 23$ & $\mathrm{~ns}$ \\
\hline $\operatorname{AST}(u / l)$ & $21 \pm 6$ & $25 \pm 9$ & ns \\
\hline $\operatorname{ALT}(\mathbf{u} / \mathbf{l})$ & $20 \pm 8$ & $26 \pm 9$ & $\mathrm{~ns}$ \\
\hline CK (u/l) & $114 \pm 53$ & $128 \pm 150$ & ns \\
\hline Gamma-GT (u/l) & $\begin{array}{l}26 \\
(10-200)\end{array}$ & $\begin{array}{l}18 \\
(8-494)\end{array}$ & $\mathrm{ns}$ \\
\hline Glucose (mg/dl) & $158 \pm 52$ & $119 \pm 19$ & 0.005 \\
\hline $\mathrm{HbA}_{1 \mathrm{c}}(\%)$ & $6.8 \pm 1.5$ & $5.7 \pm 0.8$ & N/A \\
\hline $\mathrm{Cr}(\mathrm{mg} / \mathrm{dl})$ & $1 \pm 0.3$ & $0.9 \pm 0.2$ & $\mathrm{~ns}$ \\
\hline Leptin (ng/ml) & $10.6 \pm 7.3$ & $4.5 \pm 2.6$ & 0.003 \\
\hline Adiponectin $(\mu \mathrm{g} / \mathrm{ml})$ & $17.5 \pm 9.2$ & $18.7 \pm 18.2$ & $\mathrm{~ns}$ \\
\hline Ghrelin (pg/ml) & $818 \pm 255$ & $662 \pm 285$ & ns \\
\hline NPY (pmol/L) & $85.8 \pm 30.9$ & $108 \pm 36.7$ & $\mathrm{~ns}$ \\
\hline MDRD eGFR (mL/min/1.73 m²) & $83.5 \pm 20.4$ & $93.8 \pm 27$ & ns \\
\hline Cockroft-Gault creatinine clearance (mL/min) & $82.8 \pm 25.5$ & $89.7 \pm 25.6$ & ns \\
\hline
\end{tabular}

For abbreviations see Table 1.

(e.g. leptin resistance, obesity and stress). Further research is needed to clarify the role of peripheral and central NPY levels on appetite control.

Apart from appetite, NPY has been associated with intense or prolonged stress, leading to vasoconstriction and angiogenesis [37]. Interestingly, plasma NPY concentrations were reported to be increased due to enhanced sympathetic activation in stress-related cardiac conditions [38].

Therefore, an increase in circulating NPY levels cannot be attributed separately to changes in nutritional or stress status.

Of note, in patients on hemodialysis, plasma NPY concentrations were elevated due to both a poor state of nourishment and fluid volume overload-induced stress [39].
Body fat has been proposed as the best predictor of leptin levels in humans independently of gender [40]. In the present study a non significant increase in the percentage of body fat was observed following insulin therapy, as reported by others [29]. Interestingly, a significant insulin-related increase in both subcutaneous fat area and fat mass was also observed in T2DM patients [29, 30]. These discrepancies may be attributed to differences in methodology (e.g. definition of body fat).

In our study, leptin levels correlated with body fat (\%) and WC in all groups, except group B males. Similarly, WC correlated with leptin concentrations in Asian-Indian patients with impaired glucose tolerance or T2DM [41, 42]. In the present study, changes in leptin levels did not correlate with $\mathrm{HbA}_{1 \mathrm{c}}$, as reported by Aas et al., [30]. 
Table 6. Fasting Laboratory and Other Characteristics of Female Patients with Type 2 Diabetes Mellitus at 6 Months

\begin{tabular}{|c|c|c|c|}
\hline & Group A $(n=19)$ & Group B $(n=30)$ & $\mathbf{p}$ \\
\hline Weight (kg) & $73.3 \pm 21.2$ & $76.2 \pm 14.4$ & ns \\
\hline BMI $\left(\mathrm{kg} / \mathrm{m}^{2}\right)$ & $28.8 \pm 7.9$ & $31.4 \pm 5.1$ & ns \\
\hline Waist circumference (cm) & $101 \pm 18.1$ & $105.7 \pm 12.8$ & ns \\
\hline Body Fat (\%) & $41.4 \pm 13.3$ & $47.5 \pm 7.4$ & ns \\
\hline SBP (mmHg) & $139.7 \pm 24.6$ & $139.5 \pm 11.7$ & ns \\
\hline DBP (mmHg) & $79.2 \pm 12.6$ & $78.6 \pm 8.3$ & ns \\
\hline $\operatorname{WCC}\left(\times 10^{3} / \mu \mathrm{l}\right)$ & $7186 \pm 1859$ & $7418 \pm 1671$ & ns \\
\hline Uric acid (mg/dl) & $4.8 \pm 1.4$ & $5.4 \pm 1.4$ & ns \\
\hline TC (mg/dl) & $198 \pm 35$ & $191 \pm 34$ & ns \\
\hline TG (mg/dl) & $145 \pm 79$ & $161 \pm 71$ & ns \\
\hline HDL-C (mg/dl) & $60 \pm 19$ & $52 \pm 13$ & ns \\
\hline LDL-C (mg/dl) & $109 \pm 35$ & $115 \pm 54$ & ns \\
\hline $\operatorname{AST}(u / l)$ & $22 \pm 9$ & $17.2 \pm 6.9$ & ns \\
\hline $\operatorname{ALT}(\mathbf{u} / \mathbf{l})$ & $23 \pm 11$ & $22 \pm 9$ & ns \\
\hline CK (u/l) & $103 \pm 71$ & $87 \pm 53$ & ns \\
\hline Gamma-GT (u/l) & $\begin{array}{l}19 \\
(9-299)\end{array}$ & $\begin{array}{l}16 \\
(7-56)\end{array}$ & ns \\
\hline Glucose (mg/dl) & $142 \pm 55$ & $139 \pm 35$ & ns \\
\hline $\mathrm{HbA}_{1 \mathrm{c}}(\%)$ & $6.9 \pm 1.5$ & $6.3 \pm 1.1$ & ns \\
\hline $\mathrm{Cr}(\mathrm{mg} / \mathrm{dl})$ & $0.8 \pm 0.2$ & $0.8 \pm 0.2$ & ns \\
\hline Leptin (ng/ml) & $23.3 \pm 12.8$ & $17.4 \pm 7.9$ & ns \\
\hline Adiponectin $(\mu \mathrm{g} / \mathrm{ml})$ & $18.3 \pm 14.1$ & $24.9 \pm 19.7$ & ns \\
\hline Ghrelin (pg/ml) & $874 \pm 346$ & $542 \pm 312$ & $<0.001$ \\
\hline NPY (pmol/L) & $96.9 \pm 31.1$ & $131.1 \pm 56.9$ & 0.01 \\
\hline MDRD eGFR (mL/min/1.73 $\left.\mathrm{m}^{2}\right)$ & $87.6 \pm 25.4$ & $83 \pm 25.5$ & ns \\
\hline Cockroft-Gault creatinine clearance $(\mathrm{mL} / \mathrm{min})$ & $96.4 \pm 49.7$ & $91.4 \pm 34.8$ & ns \\
\hline
\end{tabular}

For abbreviations see Table $\mathbf{1}$.

Patients on OHAs did not show any change in weight or leptin levels throughout the study, as previously reported [30]. Group B females were the only patients to show significant reduction in both ghrelin levels and body fat. These results may be because they had the highest body fat (50.7 \pm $7.9 \%)$ at baseline and the greatest reduction (33\%) in ghrelin levels throughout the study compared with the other groups.

Throughout the study, TG levels significantly decreased $(\mathrm{p}=0.006)$ and HDL-C levels significantly increased $(\mathrm{p}=$ 0.002 ) only in group A females. These results may be attributed to the insulin-induced improvement of $\mathrm{HbA}_{1 \mathrm{c}}$, as good glycaemic control exerts beneficial effects on lipids in T2DM patients [28].

DBP significantly decreased in group A females 6 months after initiation of insulin therapy $(p=0.003)$. In this context, others [43] reported a significant positive association of mean $\mathrm{HbA}_{1 \mathrm{c}}$ and DBP in patients with type 1 diabetes mellitus (T1DM); no data were found for T2DM patients.

Renal function indices did not change significantly throughout the study in all groups. However, all our patients had normal kidney function. In contrast, abnormal baseline GFR values in patients with T1DM improved significantly following intensive insulin treatment [44]; no data were found for T2DM patients.

Several drugs frequently prescribed to diabetic patients have been shown to influence leptin, adiponectin and/or ghrelin levels [45]. In detail, OHAs have been reported to differentially influence plasma levels of leptin, adiponectin and ghrelin [11-14, 46-48], whereas there were no reports for NPY. Antihypertensive agents were shown to either increase 
Table 7. Correlations Between Waist Circumference, Body Fat and Leptin Levels Observed Throughout the Study

\begin{tabular}{|c|c|c|c|c|c|c|c|}
\hline & \multicolumn{3}{|c|}{$\begin{array}{c}\text { Male Patients } \\
\text { Group A }\end{array}$} & \multicolumn{4}{|c|}{ Female Patients } \\
\hline & & Correlation Coefficient & $\mathbf{p}$ & Correlation Coefficient & $\mathbf{p}$ & Correlation Coefficient & $\mathbf{p}$ \\
\hline \multirow[t]{2}{*}{ Baseline } & Leptin - WC & rho $=0.812$ & $<0.001$ & rho $=0.653$ & 0.002 & $\mathrm{r}=0.61$ & $<0.001$ \\
\hline & Leptin - body fat & rho $=0.664$ & $<0.001$ & rho $=0.72$ & 0.001 & $\mathrm{r}=0.566$ & 0.001 \\
\hline \multicolumn{3}{|r|}{ Correlation Coefficient } & $\mathbf{p}$ & Correlation Coefficient & $\mathbf{p}$ & Correlation Coefficient & $\mathbf{p}$ \\
\hline \multirow[t]{3}{*}{3 months } & Leptin - WC & rho $=0.764$ & $<0.001$ & rho $=0.725$ & 0.001 & $\mathrm{r}=0.606$ & $<0.001$ \\
\hline & Leptin - body fat & rho $=0.668$ & $<0.001$ & rho $=0.772$ & $<0.001$ & $\mathrm{r}=0.538$ & 0.002 \\
\hline & WC - body fat & $\mathrm{r}=0.725$ & $<0.001$ & $\mathrm{r}=0.799$ & $<0.001$ & $\mathrm{r}=0.512$ & 0.004 \\
\hline \multirow{2}{*}{6 months } & Leptin - body fat & rho $=0.469$ & 0.016 & $\mathrm{r}=0.641$ & 0.003 & $\mathrm{r}=0.641$ & 0.003 \\
\hline & WC - body fat & $\mathrm{r}=0.632$ & 0.01 & $\mathrm{r}=0.752$ & $<0.001$ & $\mathrm{r}=0.587$ & 0.001 \\
\hline
\end{tabular}

WC: waist circumference.

[49] or reduce leptin [50] and to increase adiponectin levels in T2DM patients $[51,52]$. No data were found regarding the influence of these agents on ghrelin and NPY levels in T2DM patients. In these patients lipid-lowering drugs were also reported to reduce leptin $[53,54]$ and increase adiponectin concentrations $[12,55]$. In contrast, ghrelin levels did not change following short-term (6 weeks) treatment with either atorvastatin or fenofibrate in diabetic patients with mixed hyperlipoproteinaemia [56]. There are no data concerning the effects of lipid-modifying agents on NPY concentrations.

In our study no patient was on fibrate therapy but almost half of them were taking statins and even more patients were on antihypertensive agents. The study groups did not differ significantly in statin and antihypertensive use and these treatments remained unchanged throughout the study. Nevertheless, the use of different drugs in our patients is a limitation of our study as is the small sample size which did not allow multivariate analysis. However, other studies in this field [29-33] had similar patient numbers and did not analyze their results by gender. Furthermore, the measured parameters are interrelated and the influence of each individual factor on insulin-related body weight gain is difficult to identify.

\section{CONCLUSIONS}

In the present study, initiation of insulin treatment was associated with a significant increase in leptin levels and a significant decrease in NPY levels in both genders. These effects should have suppressed appetite and reduced food consumption, leading to weight loss. In contrast, all insulintreated patients gained weight, possibly due to other mechanisms such as the anabolic effects of insulin, stimulation of lipogenesis, suppression of hepatic glucose production, re- duction of basal metabolic rate and elimination of glycosuria. It is also possible that leptin resistance may be partly responsible for the observed weight increase.

In general, changes in leptin, adiponectin and NPY levels may occur following insulin-induced improved glycaemic control. These changes may be influenced by several variables, including gender, weight, body fat and glycaemic control. The interactions between these factors were not considered in previous studies.

It is possible that targeting the peptides measured in this study could influence weight gain after insulin treatment.

\section{DECLARATION OF INTEREST}

This paper was written independently. The authors did not receive financial or professional help with the preparation of the manuscript.

DPM has given talks, attended conferences and participated in advisory boards and trials sponsored by various pharmaceutical companies (MSD, Genzyme, Astra-Zeneca).

\section{ACKNOWLEDGEMENTS}

NK is supported by a grant from the Northern Greece Diabetes Association and a grant from the Hellenic Atherosclerosis Society.

We thank Dr. GE Krassas, Head of the Department of Endocrinology, Diabetes and Metabolism, Panagia General Hospital, Thessaloniki, Greece, for his advice and assistance in recruiting patients.

\section{REFERENCES}

[1] Heller S. Weight gain during insulin therapy in patients with type 2 diabetes mellitus. Diab Res Clin Pract 2004; 65S: S23-7. 
[2] United Kingdom Prospective Diabetes Study. Intensive bloodglucose control with sulphonylureas or insulin compared with conventional treatment and risk of complications in patients with type 2 diabetes (UKPDS 33). Lancet 1998; 352: 837-53.

[3] Russell-Jones D, Khan R. Insulin-associated weight gain in diabetes: causes, effects and coping strategies. Diabetes Obes Metab 2007; 9: 799-812.

[4] Kersten S. Mechanisms of nutritional and hormonal regulation of lipogenesis. EMBO Rep 2001; 2: 282-6.

[5] Yki-Järvinen H, Ryysy L, Kauppila M, et al. Effect of obesity on the response to insulin therapy in noninsulin-dependent diabetes mellitus. J Clin Endocrinol Metab 1997; 82: 4037-43.

[6] Porte D Jr, Baskin DG, Schwartz MW. Insulin signalling in the central nervous system: a critical role in metabolic homeostasis and disease from C. elegans to humans. Diabetes 2005; 54: 1264-76.

[7] Havel PJ. Peripheral signals conveying metabolic information to the brain: short-term and long-term regulation of food intake and energy homeostasis. Exp Biol Med 2001; 226: 963-77.

[8] Stanley S, Wynne K, McGowan B, Bloom S. Hormonal regulation of foods intake. Physiol Rev 2005; 85: 1131-58.

[9] Dridi S, Taouis M. Adiponectin and energy homeostasis: consensus and controversy. J Nutr Biochem 2009; 20: 831-9.

[10] Nakazato M, Murakami N, Date Y, et al. A role for ghrelin in the central regulation of feeding. Nature 2001; 409: 194-8.

[11] Kim HJ, Kim SK, Shim WS, et al. Rosiglitazone improves insulin sensitivity with increased serum leptin levels in patients with type 2 diabetes mellitus. Diabetes Res Clin Pract 2008; 81: 42-9.

[12] Chu CS, Lee KT, Lee MY, et al. Effects of rosiglitazone alone and in combination with atorvastatin on non-traditional markers of cardiovascular disease in patients with type 2 diabetes mellitus. Am J Cardiol 2006; 97: 646-50

[13] Tsuchiya K, Akaza I, Yoshimoto T, Hirata Y. Pioglitazone improves endothelial function with increased adiponectin and highdensity lipoprotein cholesterol levels in type 2 diabetes. Endocr $\mathrm{J}$ 2009; 56: 691-8.

[14] Kadoglou NP, Tsanikidis H, Kapelouzou A, et al. Effects of rosiglitazone and metformin treatment on apelin, visfatin, and ghrelin levels in patients with type 2 diabetes mellitus. Metabolism 2010; 59: 373-9.

[15] Ariyasu H, Takaya K, Hosoda H, et al. Delayed short-term secretory regulation of ghrelin in obese animals: evidenced by a specific RIA for the active form of ghrelin. Endocrinology 2002; 143: 3341-50.

[16] Murakami N, Hayashida T, Kuroiwa $\mathrm{T}$, et al. Role for central ghrelin in food intake and secretion profile of stomach ghrelin in rats. J Endocrinol 2002; 174: 283-8.

[17] Kusuoka H, Hoffman J. Advice on statistical analysis for circulation research. Circ Res 2002; 91: 662-71.

[18] Widjaja A, Stratton IM, Horn R, Holman RR, Turner R, Brabant G. UKPDS 20: plasma leptin, obesity and plasma insulin in type 2 diabetic subjects. J Clin Endocrinol Metab 1997; 82: 654-7.

[19] Schäffler A, Herfarth H, Paul G, et al. Identification of influencing variables on adiponectin serum levels in diabetes mellitus type 1 and type 2. Exp Clin Endocrinol Diabetes 2004; 112: 383-9.

[20] Little RR, Sacks DB. HbA1c: how do we measure it and what does it mean? Curr Opin Endocrinol Diabetes Obes 2009; 16 : 113-8.

[21] Ludescher B, Machann J, Eschweiler GW, et al. Correlation of fat distribution in whole body MRI with generally used anthropometric data. Invest Radiol 2009; 44: 712-9.

[22] Nishizawa H, Shimomura I, Kishida K, et al. Androgens decrease plasma adiponectin, an insulin-sensitizing adipocyte-derived protein. Diabetes 2002; 51: 2734-41.

[23] Putz DM, Goldner WS, Bar RS, Haynes WG, Sivitz WI. Adiponectin and C-reactive protein in obesity, type 2 diabetes and monodrug therapy. Metabolism 2004; 53: 1454-61.

[24] Purnell JQ, Weigle DS, Breen P, Cummings DE. Ghrelin levels correlate with insulin levels, insulin resistance and high-density lipoprotein cholesterol, but not with gender, menopausal status or cortisol levels in humans. J Clin Endocrinol Metab 2003; 88: 574752.

[25] Greenman Y, Rouach V, Limor R, Gilad S, Stern N. Testosterone is a strong correlate of ghrelin levels in men and postmenopausal women. Neuroendocrinology 2009; 89: 79-85.

[26] Ueno H, Shiiya T, Mizuta M, Mondal SM, Nakazato M. Plasma ghrelin concentrations in different clinical stages of diabetic com- plications and glycemic control in Japanese diabetics. Endocr J 2007; 54: 895-902.

[27] Katsuki A, Urakawa H, Gabazza EC, et al. Circulating levels of active ghrelin is associated with abdominal adiposity, hyperinsulinemia ands insulin resistance in patients with type 2 diabetes mellitus. Eur J Endocrinol 2004; 151: 573-7.

[28] Vaverkova H, Chlup R, Ficker L, Novotny D, Bartek J. Complementary insulin therapy improves blood glucose and serum lipid parameters in type 2 (non-insulin-dependent) diabetic patients. II. Effects on serum lipids, lipoproteins and apoproteins. Exp Clin Endocrinol Diabetes 1997; 105(Suppl 2): 74-7.

[29] Jacob AN, Salinas K, Adams-Huet B, Raskin P. Weight gain in type 2 diabetes mellitus. Diabetes Obes Metab 2007; 9: 386-93.

[30] Aas AM, Hanssen KF, Berg JP, Thorsby PM, Birkeland KI. Insulin-stimulated increase in serum leptin levels precedes and correlates with weight gain during insulin therapy in type 2 diabetes. $\mathrm{J}$ Clin Endocrinol Metab 2009; 94: 2900-6.

[31] Aas AM, Seljeflot I, Torjesen PA, Diep LM, Thorsby PM, Birkeland KI. Blood glucose lowering by means of lifestyle intervention has different effects on adipokines as compared with insulin treatment in subjects with type 2 diabetes. Diabetologia 2006; 49: 872-80

[32] Carey PE, Stewart MW, Ashworth L, Taylor R. Effect of insulin therapy on plasma leptin and body weight in patient with type 2 diabetes. Horm Metab Res 2003; 35: 372-6.

[33] Miyashita Y, Nishimura R, Nemoto M, et al. Prospective randomized study for optimal insulin therapy in type 2 diabetic patients with secondary failure. Cardiovasc Diabetol 2008; 7: 16.

[34] Kos K, Harte AL, James S, et al. Secretion of neuropeptide Y in human adipose tissue and its role in maintenance of adipose tissue mass. Am J Physiol Endocrinol Metab 2007; 293: E1335-40.

[35] Ahima RS, Qi Y, Singhal NS. Adipokines that link obesity and diabetes to the hypothalamus. Prog Brain Res 2006; 153: 155-74.

[36] Kastin AJ, Akerstrom V. Nonsaturable entry of neuropeptide Y into brain. Am J Physiol 1999; 276: E479-82.

[37] Zukowska Z, Grant DS, Lee EW. Neuropeptide Y: a novel mechanism for ischemic angiogenesis. Trends Cardiovasc Med 2003; 13: 86-92.

[38] McDermott BJ, Bell D. NPY and cardiac diseases. Curr Top Med Chem 2007; 7: 1692-703.

[39] Akagi S, Nagake Y, Sugimoto T, et al. Plasma neuropeptide $\mathrm{Y}$ concentrations in patients on hemodialysis. Nephron 2002; 92: 333-8.

[40] Hickey MS, Israel RG, Gardiner SN, et al. Gender differences in serum leptin levels in humans. Biochem Mol Med 1996; 59: $1-6$.

[41] Marita AR, Sarkar JA, Rane S. Type 2 diabetes in non-obese Indian subjects is associated with reduced leptin levels: study from Mumbai, Western India. Mol Cell Biochem 2005; 275: 143-51.

[42] Lele RD, Joshi SR, Gupte A. Association of adipocytokines (leptin, adiponectin, TNF-alpha), insulin and proinsulin with diabetes- the Mumbai Obesity Project (MOP). J Assoc Physicians India 2006; 54: 689-96.

[43] Torchinsky MY, Gomez R, Rao J, Vargas A, Mercante DE, Chalew SA. Poor glycemic control is associated with increased diastolic blood pressure and heart rate in children with Type 1 diabetes. J Diabetes Complications 2004; 18: 220-3.

[44] Christensen CK, Christiansen JS, Schmitz A, Christensen T, Hermansen K, Mogensen CE. Effect of continuous subcutaneous insulin infusion on kidney function and size in IDDM patients: a 2 year controlled study. J Diabet Complications 1987; 1: 91-5.

[45] Katsiki N, Mikhailidis DP, Gotzamani-Psarrakou A, Yovos JG, Karamitsos D. Effect of various treatments on leptin, adiponectin, ghrelin and neuropeptide $\mathrm{Y}$ in patients with type 2 diabetes mellitus. Expert Opin Ther Targets 2011; 15: 401-20.

[46] Adamia N, Virsaladze D, Charkviani N, Skhirtladze M, Khutsishvili $M$. Effect of metformin therapy on plasma adiponectin and leptin levels in obese and insulin resistant postmenopausal females with type 2 diabetes. Georgian Med News 2007; 145: 52-5.

[47] Doogue MP, Begg EJ, Moore MP, Lunt H, Pemberton CJ, Zhang M. Metformin increases plasma ghrelin in type 2 diabetes. $\mathrm{Br} \mathrm{J}$ Clin Pharmacol 2009; 68: 875-82.

[48] Araki T, Emoto M, Konishi T, et al. Glimepiride increases high-density lipoprotein via increasing adiponectin levels in type 2 diabetes mellitus. Metabolism 2009, 58: 143-8. 
[49] Usui I, Fujisaka S, Yamazaki K, et al. Telmisartan reduced blood pressure and HOMA-IR with increasing plasma leptin level in hypertensive and type 2 diabetic patients. Diabetes Res Clin Pract 2007; 77: 210-4.

[50] Derosa G, Cicero AF, D'Angelo A, et al. Telmisartan and irbesartan therapy in type 2 diabetic patients treated with rosiglitazone: effects on insulin-resistance, leptin and tumor necrosis factor-alpha. Hypertens Res 2006; 29: 849-56.

[51] Fuke Y, Fujita T, Satomura A, Wada Y, Matsumoto K. Alterations of insulin resistance and the serum adiponectin level in patients with type 2 diabetes mellitus under the usual antihypertensive dosage of telmisartan treatment. Diabetes Technol Ther 2010; 12: 3938.

[52] Nomura S, Inami N, Kimura $\mathrm{Y}$, et al. Effect of nifedipine on adiponectin in hypertensive patients with type 2 diabetes mellitus. J Hum Hypertens 2007; 21: 38-44.
[53] Damci T, Tatliagac S, Osar Z, Ilkova H. Fenofibrate treatment is associated with better glycemic control and lower serum leptin and insulin levels in type 2 diabetic patients with hypertriglyceridemia. Eur J Intern Med 2003; 14: 357-60.

[54] von Eynatten M, Schneider JG, Hadziselimovic S, et al. Adipocytokines as a novel target for the anti-inflammatory effect of atorvastatin in patients with type 2 diabetes. Diabetes Care 2005; 28: 754-5.

[55] $\mathrm{Hu} \mathrm{Y}$, Tong $\mathrm{G}, \mathrm{Xu} \mathrm{W}$, et al. Anti-inflammatory effects of simvastatin on adipokines in type 2 diabetic patients with carotid atherosclerosis. Diab Vasc Dis Res 2009; 6: 262-8.

[56] Otto C, Otto B, Frost RJ, et al. Short-term therapy with atorvastatin or fenofibrate does not affect plasma ghrelin, resistin or adiponectin levels in type 2 diabetic patients with mixed hyperlipoproteinaemia. Acta Diabetol 2007; 44: 65-8.

(C) Katsiki et al.; Licensee Bentham Open.

This is an open access article licensed under the terms of the Creative Commons Attribution Non-Commercial License (http://creativecommons.org/licenses/ by-nc/3.0/) which permits unrestricted, non-commercial use, distribution and reproduction in any medium, provided the work is properly cited. 